ESTUDIOS 



\title{
EL VALOR DE POSICIÓN DE LA CARTA DE DERECHOS FUNDAMENTALES EN LA COMUNIÓN CONSTITUCIONAL EUROPEA ${ }^{1}$
}

\author{
PEDRO CRUZ VILLALÓN \\ Catedrático Emérito de Derecho Constitucional \\ Universidad Autónoma de Madrid
}

«El valor de un catálogo detallado de derechos y deberes como el que contiene la Carta de Derechos Fundamentales no es sin embargo comparable al de la deducción de posiciones juridicas a partir de principios generales del Derecho» ${ }^{2}$.

(Sentencia de 14 de marzo de 2012, del Tribunal Constitucional de Austria)

\section{SUMARIO}

I. La Carta en la comunión constitucional europea. II. El valor de posición de la Carta, a partir de la propia CDF: la Carta como deidad bifronte. III. El valor de posición de la Carta más allá de la CDF: constitucionalización espontánea de la Carta.

La Carta de Derechos Fundamentales de la Unión Europea (en adelante, la Carta, o la $\mathrm{CDF})^{3}$ es hoy día, por excelencia, el vaso comunicante por el que

1 El presente texto deriva, con bastantes cambios, de la conferencia pronunciada el 1 de octubre de 2015 en la sede y por invitación del Tribunal Constitucional de la República de Austria en la ceremonia anual conmemorativa de su Ley Constitucional Federal, con el título «Der Stellenwert der Grundrechte-Charta im europäischen Verfassungsverbund», publicado en edición bilingüe («Lugar y función de la Carta de Derechos Fundamentales en el espacio constitucional europeo»), en «Verfassungstag 2015», Verfassungsgerichtshof Österreich, Viena 2015, pp. 5-27 y 29-42. Agradezco a la Dra. Reinhild Huppmann su valiosa asistencia en la preparación y posterior actualización de este texto.

2 «Die Geltung eines detaillierten Katalogs von Rechten und Pflichten, wie ihn die Grundrechte-Charta enthält, ist aber nicht mit der Herleitung von Rechtspositionen aus allgemeinen Rechtsgrundsätzen vereinbar» (Erkenntnis vom 14. März 2012 (U 466/11-18, U 1836/11-13), 5.6. La versión inglesa de la sentencia se puede consultar en: https://www.vfgh.gv.at/downloads/grundrechtecharta_english_u466-11. pdf. Aunque volveré sobre esto más adelante, he preferido traducir en esta ocasión, «Geltung» por «valor», con preferencia a «validez», al expresar mejor, en mi criterio,el sentido original de la frase.

3 D.O.U.E. de 14 de diciembre de 2007, transcrita íntegramente a continuación del artículo 2 de la L.O. 1/2008, por la que se autoriza la ratificación del Tratado de Lisboa. 
circula la cultura de los derechos fundamentales en el espacio constitucional de la Unión. Ahora bien, esta posición, alcanzada, o acaso sólo en vías de alcanzar, de la CDF no es el exclusivo resultado de lo que el Derecho primario de la Unión, interpretado por el Tribunal de Justicia, dispone. Está siendo también, complementariamente, la obra de los Estados miembros, algunos de los cuales han aportado contribuciones específicas a la referida posición de la Carta. Prestar atención a estas aportaciones nacionales puede ser una forma adecuada de rendir un homenaje colegial, desde otro Estado miembro, a la Constitución de la República austriaca en su 95 aniversario.

Un aniversario éste que se presenta, ante todo, como una renovada ocasión para celebrar, en clave europea, el genio de una Constitución nacional que ha inspirado al constitucionalismo a lo largo del pasado siglo. Pronto hará un siglo, tomó forma en Viena la Constitución racional normativa ${ }^{4}$, tal como esencialmente la entendemos hoy en Europa ${ }^{5}$, así como la de la herramienta jurídica que, por excelencia, debía hacerla efectiva, la de un Tribunal Constitucional dotado, simplificando al máximo, del monopolio de rechazo de la ley parlamentaria contraria a la Constitución. España sería prácticamente el primero ${ }^{6}$ de los Estados europeos en seguir de cerca los pasos de esta Constitución, ya en $1931^{7}$, volviendo a hacerlo medio siglo más tarde, en un contexto bien diferente, con ocasión de la elaboración de la vigente Constitución de 1978.

Se da la circunstancia añadida de que España comparte con Austria la celebración del «Día de la Constitución» (Verfassungstag) ya sea como fiesta nacional, ya sea como Gedenktag, como también coincidieron ambos Estados en la suscripción de la Declaración aneja al Tratado de Lisboa, subrayando entre otros el valor simbólico del 9 de mayo como «Día de Europa» ${ }^{8}$. El que dos Estados europeos tan antiguos tengan una celebración, en definitiva, tan moderna tiene desde luego su explicación, que no tiene que ser la misma en ambos casos. Austria recuperó en 1945la vigencia de la Constitución de 1920, «en su versión de 1929». España, por su parte, bajo la forma ciertamente de la monarquía parlamentaria, recuperó en 1978 la sustancia de la Constitución republicana de 1931.

4 M. García-Pelayo Alonso, «Derecho Constitucional comparado». Obras Completas. Madrid, CEPC, 1991, vol. I, pp. 223-734, 260.

5 Hoy sin embargo confrontada con calificativos que a veces adquieren caracteres de oxímoron. Vid. V. VolPE, «Drafting Counter-Majoritarian Democracy — The Venice Commission's Constitutional Assistance», Zä̈RV4/2016, pp. 811-843.

6 Si prescindimos, no obstante, del caso del Principado de Lichtenstein, cuya Constitución de 1921 establece un «Staatsgerichtshof» con facultad para controlar la constitucionalidad de las leyes. H. J. STOTTER, «Die Verfassung des Fürstentums Liechtenstein», Vaduz, ex jure Verlagsanstalt, 1986.

7 Recepción con sobre abundante reflejo en el Diario de Sesiones de las Cortes Constituyentes de 1931 y de las Cortes de 1933. Me permito remitir a mi texto, «La formación del sistema europeo de control de constitucionalidad (1918-1939)», Madrid, C.E.C., 1987.

8 Declaración n. ${ }^{\circ} 52$ relativa a los símbolos de la Unión Europea, por la que 16 de los Estados miembros declaran que la bandera, el himno, la divisa, el euro y el Die de Europa «seguirán siendo, para ellos, los símbolos de la pertenencia común de los ciudadanos a la Unión Europea, y de su relación con ésta». 
Este tipo de conmemoraciones oficiales, comunes a dos Estados miembros de la Unión, expresan la convicción de que el Derecho, personificado en la primera de las leyes, sostiene nuestra convivencia como comunidad política. Pero hay incluso un dato más. El Derecho, en nuestra respectiva polis, se erige en el instrumento del poder político democrático. Ewald Wiederin lo ha expresado sin necesidad de muchas palabras: En Austria, «el demos ejerce el poder, no por medio dela fuerza, sino justamente por medio del Derecho» ${ }^{9}$. Con ello, el profesor vienés no estaba sino glosando el contenido del artículo $1 .{ }^{\circ}$ LCF: Allí donde otras Constituciones se ocupan de precisar el origen democrático del poder político, el texto fundamental austriaco opta por precisar el origen democrático del Derecho: Es «su Derecho» el que «emana del pueblo» ${ }^{10}$. La Constitución española sigue las pautas más trilladas de la soberanía nacional, pero la supremacía del Derecho es proclamada sin ambages en el artículo 9.1 CE. Ahora bien hay que reconocer que es en particular la Ley Constitucional Federal austriaca la que más expresivamente ha marcado el camino y ha facilitado la comprensión de la Unión Europea como «comunidad de Derecho». Y es de nuevo desde Austria, ahora como Estado miembro, de donde la Unión recibe inspiración para la comprensión del significado de la que desde 2009 es una pieza básica de esta comunidad de Derecho, la CDF.

\section{LA CDF EN LA COMUNIÓN CONSTITUCIONAL EUROPEA}

Austria y España, siguiendo el discurso anterior, no sólo comparten la noción de la soberanía del Derecho como clave de arco de su orden constitucional. Desde 1995, ambos Estados, y ambas Constituciones, confluyen en lo que con expresión exitosa, y por el mismo tiempo, fue calificado por Ingolf Pernice, como un «Verfassungsverbund $»^{11}$. La expresión, ciertamente no la más simple, del profesor berlinés ha sido objeto de traducciones diversas ( «plurilevel constitution», constitución «multinivel»), nunca en todo caso de forma demasiado satisfactoria. Esperando no añadir aún mayor confusión, pero buscando transmitir la especificidad del término, yo aventuraría la de comunión constitucional.

Pues, en efecto, hay que hacer en seguida esta precisión: son ambos Estados, y son ambas Constituciones las que confluyen felizmente en esta noción. Y es que no es la menor de las particularidades de esta, si se me permite, comunión constitucional su capacidad para funcionar de manera bivalente, es decir, para referirse

9 «Der demos herrscht nicht mit Gewalt, sondern eben mit Recht». «Österreich» en, A.v. BoGDANDY/ P. Cruz Villalón/Peter M. Huber, Ius Publicum Europaeum. Bd. I.C.F. Müller, Heidelberg, 2007, pp. 389-449, 419: «Das Demokratiemodell des B-VG».

10 «Ihr Recht geht vom Volke aus», Art. 1 2. Satz, B-VG.

11 I. Pernice, «Verfassungsverbund», en, C. Franzius/F.C. Mayer/J. Neyer (eds.), «Strukturfragen der Europäischen Union», Nomos, Baden-Baden, 2010, pp. 102-119. 
tanto, de una parte, a la compleja comunidad política que es la Unión Europea, como también, de otra, al complejo ordenamiento jurídico por el que la Unión se rige, siempre por referencia al orden constitucional.

En la primera de sus dimensiones, la institucional o política, nuestros dos Estados son parte de una comunión constitucional en el sentido de una comunidad supranacional de Estados a los que se debe seguir considerando soberanos. En la segunda, en su sentido normativo u ordinamental, nuestras respectivas Constituciones son parte también de una comunión constitucional en el sentido de una compleja estructura constitucional, que, por decirlo con sencillez, no se explica con el sólo principio de jerarquía.

En el primero, pues, de los sentidos, es decir, como expresión que nace muy particularmente como alternativa a la de unión de Estados («Staatenverbund»), propuesta en su día por Paul Kirchhof ${ }^{12}$, la comunión constitucional europea se sitúa en estrecha línea de continuidad con la anteriormente indicada de comunidades políticas basadas en el Derecho: La Unión Europea no es sólo «communauté de droit» sino también, de forma más específica, «communauté de constitution». Y no cabe negar la radicalidad de la apuesta de I. Pernice, al situar a la Constitución en el lugar ocupado por los Estados, como forma de dar identidad a la comunidad supranacional europea.

En el segundo de los sentidos, la expresión se ha utilizado de forma alternativa a la de constitucionalismo «multinivel». En Austria se habló, con intención parecida y durante un tiempo, de «constitución doble» o duplicada (Doppelverfassung $)^{13}$, quién sabe si como reminiscencia de la «doble monarquía» vertebrada por el Danubio. Todo ello, desde luego, siempre con algunas reservas respecto de la oportunidad de esta expresión, como las formuladas por el siempre recordado Heinz Schäffer hace ya una década ${ }^{14}$. En España, por su parte, la expresión favorecida en el contexto de un constitucionalismo complejo, del «bloque de constitucionalidad», de cuño conocidamente francés, no ha solido incorporar la pieza de la integración europea ${ }^{15}$. En todo caso, lo que debe subrayarse es que ambas dimensiones de la expresión, la institucional o política y la jurídica habrán de ser tratadas en paralelo a lo largo de las páginas que siguen.

¿Debe también incorporarse aquí la formulación propuesta por el Presidente del Tribunal Constitucional Federal alemán, Andreas Voßkuble, la de la «liga de tribunales constitucionales» europea (el «Verfassungsgerichtsverbund»)? ${ }^{16}$ Aunque

12 «The European Union of States», en, A. v. Bogdandy/J. BAST, «Principles of European Constitutional Law», 2. ${ }^{a}$ ed., Oxford, 2010.

13 P. Pernthaler, «Die neue Doppelverfassung Österreichs», Springer, 1997.

14 Celebrando este mismo «Verfassungstag»: "Grundrechte im Spannungsfeld von nationaler und europäischer Perspektive», Verfassungsgerichtshof, Viena, 2006, p. 21.

15 F. Rubio Llorente, «El bloque de constitucionalidad», REDC 27 (1989), 9-37.

16 A. Vosskuhle, «Der europäische Verfassungsgerichtsverbund», NVwZ 2010, p. 1; id., «Multilevel cooperation of the European Constitutional Courts: Der Europäische Verfassungsgerichtsverbund», European Constitutional Law Review, 6 (2010), pp. 175-198. 
de forma marginal, me parece que será inevitable hacerlo: En nuestro continente, y salvo contadas excepciones, los Tribunales Constitucionales, ya sea en sentido formal o material, son pieza inseparable de la Constitución a la que sirven.

Como parte esencial de esa comunión constitucional, en su significado normativo, aparece hoy, y desde hace siete años, la «Carta de Derechos Fundamentales de la Unión Europea», compartida consiguientemente por Austria y España como Estados miembros, si bien, como veremos, con peculiaridades añadidas en cada caso. Ciertamente no es esta la primera tabla de derechos y libertades que comparten nuestros Estados: desde 1977 España es parte en el Convenio Europeo de Derechos humanos y Libertades fundamentales al que ya se encontraba integrada Austria desde 1958, pero la Carta «de Lisboa», es de otra naturaleza. Es esta una declaración de derechos que compartimos, no como nacionales de Estados diversos, sino como miembros de una misma comunidad política, partícipes de una misma ciudadanía.

Es claro que, en una versión muy semejante a la actual, la Carta disfrutaba ya de una determinada existencia desde hacía una década, en concreto, bajo la sola condición de declaración de derechos solemnemente proclamada, aunque ni «promulgada», ni acompañada de precisión alguna respecto de su «entrada en vigor», en definitiva, sin valor jurídico ${ }^{17}$. Han sido diez sencillas palabras del Tratado de Lisboa incluidas en el TUE las que han situado a la CDF en la cúspide de la estructura constitucional de la Unión: En la formulación castellana, la CDF «tendrá el mismo valor jurídico que los Tratados» (vale decir, el TUE y el TFUE). En la formulación alemana, «la CDF y los Tratados tienen jurídicamente idéntico rango» ${ }^{18}$.

De este modo, la Carta que, ya con vocación de norma jurídica, en un determinado momento había sido proyectada como parte integrante, la segunda, del «Tratado por el que se establec(ía) una Constitución para Europa», tras el frustrado plan de un Tratado con esa ambición, era elevada al rango de Derecho primario en la nueva versión del artículo $6 \mathrm{TUE}^{19}$. En suma, la comunión constitucional europea encuentra hoy una pieza básica de su compleja estructura en un no menos complejo documento presidido por un título sin embargo escasamente equívoco: «Carta de los derechos fundamentales de la Unión Europea»: Una norma jurídica dotada del máximo rango en el ordenamiento jurídico de la Unión.

17 Para las reservas del primer momento, excelentemente argumentadas, vid, F. Rubio LlORENTE, «A Charter of Dubious Utility», International Journal of Constitutional Law, 3 (2003), pp. 405-426; id. «Mostrar los derechos sin destruir la Unión», REDC, 64 (2002), pp. 13-51.

18 «...sind rechtlich gleichrangig». Artículo 6, ap. 1, párrafo 1. ${ }^{\circ}$, segundo inciso TUE. En la versión en castellano, como parte final del único inciso del párrafo $1 .^{\circ}$, «... la cual (Carta) tendrá el mismo valor jurídico que los Tratados». La Declaración n. ${ }^{\circ} 1$ de las que acompañan al Tratado de Lisboa declara por su parte, incidentalmente, que «La Carta...tiene carácter jurídicamente vinculante...» (en lengua alemana, «Die Charta..., die rechtsverbindlich ist,...»).

19 Cfr. S. Iglesias SÁnCHez, «The Court and the Charter: the impact of the entry into force of the Lisbon Treaty on the ECJ's approach to fundamental rights», CMLR 49: 1565-1612. 2012. 
Ahora bien, inmediatamente hay que añadir que la positivación, con el indicado rango, de la CDF tiene por sí sólo un significado político innegable, que no debe ser pasado por alto. Conviene no desconocer lo que supone dotar de valor jurídico a un texto como, precisamente, una carta de derechos y libertades, equiparándola además, en este caso, a «los Tratados». La Carta, pues, como documento cuya importancia debe medirse, para comenzar, en términos políticos, es decir, en su significado para la comunidad supranacional que es la Unión. Hay que insistir, sin embargo en que, si es posible hablar de su importancia política, ello sucede porque la CDF es un documento jurídico y, sólo a partir del momento en que la CDF ha obtenido esta condición, ha comenzado a resultar posible apreciar dicha relevancia política. Pues son sus específicos caracteres jurídicos los que dan la medida de su dimensión política: Su dimensión política es el reflejo de sus caracteres jurídicos.

Desde esta perspectiva, y si no fuera porque la Carta es directamente Derecho, bien hubiera podido venir a sumarse a los símbolos de Europa enumerados en la referida Declaración n. ${ }^{\circ} 52$ del Tratado de Lisboa. Y es que, en esta misma línea, una carta de derechos no necesita nunca de muchas palabras: Es «constitucional» en su forma y en su fondo. Si la frustrada Constitución para Europa, de 2004, no pudo evitar la longitud, casi desmintiendo su propio nombre, la Carta por su parte es, a fin de cuentas, un documento en su mayor parte sencillo. Ha sido desde esa perspectiva una suerte el que no haya aparecido de algún modo perdida en tanto que inmersa en un inacabable tratado constitucional ${ }^{20}$.

En definitiva, la Carta opera un «cambio de paradigma» en el modo de asumir la garantía de los derechos y libertades ${ }^{21}$. Por medio de la Carta, los derechos fundamentales dejan de pertenecer a los jueces, dicho sea con un sentido neutro, para pasar a tomar cuerpo en una gramática sin duda necesitada de interpretación, pero menos de creatividad. Y es que, en ausencia de una arraigada tradición de common law, como es casi siempre el caso en el espacio constitucional europeo, la positivización de los derechos y libertades adquiere particular importancia. Baste pensar en el polémico asunto Mangold ${ }^{22}$ : El principio de prohibición de discriminación por razón de la edad hubiera sido recibido con menos resistencia por nuestros compatriotas alemanes ${ }^{23}$ si en lugar de resultar de un anclaje —o acaso de una excavación - en los principios generales del Derecho de la Unión, hubiera resultado de una simple invocación de la literalidad del artículo 21 CDF.

20 P. Cruz Villalón, «Sobre 'las disposiciones generales que rigen la interpretación y aplicación de la Carta'», en F. Rubio Llorente et. al., «La Constitución Política de España. Estudios en homenaje a Manuel Aragón Reyes», Madrid, CEPC, 2016, pp. 573-586.

21 P. Cruz Villalón, «The 'added value' of the Charter in relation to the ECHR», en «Igualdad y democracia. Estudios en homenaje a la profesora Julia Sevilla», Valencia, 2014, pp. 209-214.

22 Sentencia del TJUE (C-144/04) de 22 de noviembre de 2005.

23 Expresivamente, R. Herzog, «Stoppt den Europäischen Gerichtshof!», Frankfurter Allgemeine Zeitung, 8.9.2008. 
En el contexto de este «cambio de paradigma» resulta obligado adelantar una referencia a la sentencia del Tribunal Constitucional austriaco de 14 de marzo de $2012^{24}$. Con independencia de que más adelante vuelva sobre ella, y en primer lugar a las circunstancias del caso, me limitaré a la cita de un pasaje clave de la misma que habla por sí solo: «La jurisprudencia constitucional recaída en relación con el Derecho de la Unión con anterioridad a la entrada en vigor del Tratado de Lisboa no puede ser extendida a la Carta de Derechos Fundamentales». Esa necesidad de innovar se impone, continúa el Tribunal, desde el momento en que la Carta «constituye, en el conjunto del Derecho de la Unión, un ámbito claramente delimitado respecto de los "Tratados" (como lo prueba el mismo lenguaje del art. 6 TUE: La Carta $y$ los Tratados), que debe ser objeto de tratamiento diferenciado en el interior del ordenamiento constitucional interno» ${ }^{25}$. Como la propia sentencia continúa diciendo, y en los términos recogidos en la cabecera de estas páginas, «el valor de un catálogo detallado de derechos y deberes como el que contiene la Carta de Derechos Fundamentales no es comparable a la operación de deducción de posiciones jurídicas a partir de principios generales del Derecho» (38), con las consecuencias que más adelante se expresarán. En definitiva, la CDF es expresión de un llamamiento a un «cambio de paradigma», vacilante si se quiere, pero inconfundible en sí mismo, y esto es lo que la resolución austriaca en cuestión constata.

\section{EL «VALOR DE POSICIÓN» DE LA CARTA, A PARTIR DE LA PROPIA CDF: LA CARTA COMO DEIDAD BIFRONTE}

La entrada en vigor de la CDF en 2009 ha supuesto un reto formidable, en términos puramente científicos, pues ésa creo que es la palabra, no comparable al

24 S. MAYR, «Verfassungserichtlicher Prüfungsgegenstand und Prüfungsmassstab im Spannungsfeld nationaler, konventions- und unionsrechtlicher Gewährleistungen», ZfV (2012), 401; F. MERLI, «Umleitung der Rechtsgeschichte», Journal für Rechtspolitik, 20 (2012) 355-361; M. PösCHL, «Verfassungsgerichtsbarkeit nach Lissabon. Anmerkungen zum Charta-Erkenntnis des VfGH», ZÖR (2012) 67: 587-609; G. KRISTOFERITSCH, «The Charter of fundamental rights of the European Union to be treated like Constitutional Law. Austrian Constitutional Court. Judgment of 14 March 2012, U 466/11 et al», Vienna Journal of International Constitutional Law, (2013) 7: 88-92; H. VERDINO, «The Charter of Fundamental Rights of the European Union as review standard in proceedings before the Constitutional Court», ibid., pp. 93-94; Chr. BezemeK, «Wording and Determinatedness - Indeterminately Worded», ibid. pp. 95-98; K. LACHMAYER, «The Austrian Approach towards European Human Rights», ibid., 105-107; C. FuCHs, «An Austrian enthusiasm towards European human rights protection. Some shorts remarks on the Constitutional court's EU Charter Judgment», ibid., 108-109.

25 «5. Diese zum Recht der Europäischen Union vor dem Inkrafttreten des Vertrags von Lissabon ergangene Rechtsprechung kann nicht auf die Grundrechte-Charta übertragen werden. Sie bildet innerhalb des Unionsrechts einen von den "Verträgen" deutlich abgegrenzten Bereich (vgl. Auch Art. 6 Abs. 1 EUV: "die Charta und die Verträge") für den auf Grund der innerstaatlichen Verfassungsordnung...besonderes gilt». Hay que advertir, sin embargo, que, como se ha visto, este argumento sólo vale en cuanto basado de la versión alemana del TUE. 
que planteaba su previa existencia en letargo durante el decenio precedente. Al cabo de siete años de vigencia de la CDF todavía son varias las cuestiones básicas relativas a la Carta que el Tribunal de Justicia tiene pendientes de respuesta, y no por falta de ocasión: Baste aludir a la dicotomía derechos/principios. Pero más allá de lo que se pueda o se deba esperar del Tribunal de Justicia la doctrina tendrá que continuar situándose en una primera línea de reflexión capaz de desmenuzar la complejidad de esta norma llamada a desempeñar un papel clave en la constitucionalidad europea.

Hay en efecto muchas razones para hablar de complejidad cuando de la CDF se trata. La Carta es compleja por el mandato de coexistencia con la original radicación de los derechos fundamentales en los principios generales del Derecho de la Unión. Es compleja también, se acaba de indicar, por la diversidad de sus contenidos, los «derechos» y los «principios», y su consiguiente diverso régimen. Pero es también compleja como consecuencia de su diferente «valor de posición» (Stellenwert) en términos de posibilidad, es decir, dicho con urgencia, ante la evidencia de que una misma norma, la misma $\mathrm{CDF}$, asume un diverso valor en los diversos ordenamientos jurídicos en el que puede estar llamada a hacerse presente.

Esta es, expresada sencillamente, la cuestión de la que quisiera ocuparme en esta ocasión, haciendo un esfuerzo en dejar de lado toda una serie de cuestiones colaterales, cuyo tratamiento sería, en otro momento, inexcusable. Desde luego, no es la CDF la única norma a la que este enfoque del valor posicional puede ser aplicado. Baste pensar ya en los tratados constitutivos de la Unión según se contemplen desde la perspectiva del propio ordenamiento de la Unión, o desde la perspectiva de los «señores de los Tratados», los ordenamientos internos de los Estados miembros. O, mucho más cerca del caso español, los Estatutos de Autonomía de las Comunidades Autónomas, según se los contemple desde la perspectiva de la respectiva Comunidad Autónoma, o desde la perspectiva del Estado.

Pero el caso de la CDF es particular, también desde esta perspectiva. Como iremos viendo, la Carta es Declaración de derechos y libertades de la Unión, y es Declaración de derechos y libertades de los Estados miembros. Y aún dentro de éstos, la Carta puede mostrar diferencias de valor entre unos y otros, siendo sobre esto último sobre lo que en particular quisiera llamar la atención ${ }^{26}$.

Desde luego, habría una cuestión previa, la de la posición de la CDF en la arquitectura del artículo 6 TUE, es decir, en el conjunto del sistema de protección de los derechos fundamentales con arreglo al Derecho de la Unión. ¿Basta el hecho de que el artículo hable primero de la Carta para otorgarle una posición de primacía, se entiende respecto del paradigma de los principios generales? ¿Qué consecuencias tiene para el sistema el mandato de adhesión al CEDH? ¿Y qué

26 Ver la exposición de conjunto de K. LenAerts/J.A. Gutiérrez Fons con un título próximo a la problemática de estas páginas: «The Place of the Charter in the EU Constitutional Edifice», en, S. PEERs, T. Hervey, J. Kenner and A. Ward (eds.), «The EU Charter of Fundamental Rights. A Commentary», Hart, Oxford, 2014, pp. 1559-1593. 
consecuencias tiene la frustración, por el momento, de ese mismo mandato? Como se ve, esta cuestión previa se desglosa inmediatamente en una pluralidad de cuestiones que conviene simplemente dejar apuntadas.

Dejando esto de lado y como punto de partida, la descripción de la posición de la Carta en el espacio constitucional europeo puede ser descrita con un sencillo término, el de «bifuncionalidad». La Carta es la Declaración de Derechos de la Unión en sentido propio, vinculando a sus órganos e instituciones, y es al mismo tiempo la Declaración de Derechos de todos y cada uno de los Estados miembros, si bien sólo «cuando aplican el Derecho de la Unión». Si tuviera que recurrir a alguna imagen para describir esta posición de la Carta propondría la imagen del dios Jano, con sus dos caras, una mirando a los órganos e instituciones de la Unión, la otra mirando a los Estados miembros. La Carta, pues, situada precisamente en la puerta de comunicación entre el Derecho de la Unión y el de los Estados.

Esta bifuncionalidad otorga a la CDF su radical novedad, su condición prácticamente única. La Carta es nueva y singular en la misma medida en que es singular y única la propia comunidad política a la que se dirige. De algún modo, la singular naturaleza de la comunión constitucional que es la Unión anunciaba ya la condición bifuncional que asumiría la Carta.

Pero la funcionalidad de cada una de las caras de nuestra deidad bifronte es diferente. Cuando mira («se dirige») a los órganos e instituciones de la Unión, la CDF detenta una posición de monopolio o exclusividad, completada por una nota de incondicionalidad. Cuando mira a los Estados la deidad se ve confrontada con otros rostros, otros rostros de expresión acaso airada, que le recuerdan precisamente su condicionalidad.

Cara a la Unión la Carta puede presumir de una posición de «monopolio» o de exclusividad, porque la Unión está sometida a una única carta de derechos y libertades, si se me permite dejar de lado la señalada complejidad derivada de la arquitectura del artículo 6 TUE. Esta posición es ahora tanto más cierta como consecuencia de la desautorización de los proyectos de acuerdo en el seno del Consejo de Europa que hubieran implementado la previsión del TUE relativa al acceso de la Unión al CEDH ${ }^{27}$.

Esta posición de monopolio o exclusividad debe ser reforzada por una nota de incondicionalidad, por contraste con lo que se dirá inmediatamente: La Carta se aplica a todas las manifestaciones jurídicas del Derecho de la Unión o, dicho más exactamente, a todo su derecho derivado. Pues, por lo que hace al derecho originario éste es, por definición, no contrastable con la Carta, sin que deba olvidarse que es el Tratado el que otorga valor jurídico, el que sabemos, a la CDF.

Lo importante es que la CDF se convierte en parámetro preciso de la constitucionalidad ius-fundamental de todos los actos de los poderes públicos de la

27 Dictamen 2/2013, del Pleno del TJUE, de 18 de diciembre de 2014. 
Unión, en unos términos que no han exigido extraordinarios problemas de interpretación, aparte algunas cuestiones como la eficacia retroactiva de la $\mathrm{CDF}^{28}$.Es, por dar uno de los ejemplos más conocidos, con el instrumento de la Carta como el Tribunal de Justicia ha declarado la nulidad de la Directiva que incorporó el mandato de retención de datos ${ }^{29}$.

Por el contrario, cuando la Carta mira («se dirige») a los Estados miembros encuentra un espacio en cierto modo «ya ocupado», un espacio que debe compartir con la particular y respectiva declaración de derechos y libertades contenida normalmente en las respectivas Constituciones nacionales. La CDF pretende «superponerse» así a las cartas nacionales, con vocación de desplazamiento, con independencia de lo que inmediatamente se diga. Es claro que estas expresiones encubren una variedad de problemas formidables que van a dejarse en esta ocasión de lado: la CDF no anula los derechos y libertades nacionales, incluso en el ámbito de aplicación del Derecho de la Unión, como el Tribunal de Justicia ha venido a reconocer en el conocido punto 29 del asunto $A$ kerberg $^{30}$.

La Carta, pues, «se dirige» a los Estados miembros. Pero, aunque en este caso no haya una mención a las distintas autoridades públicas de los Estados, es claro que se está proclamando un efecto tan «directo» sobre estas autoridades públicas como es el caso de los órganos e instituciones de la Unión a los que el precepto menciona. Por decir lo más evidente, no hay necesidad alguna de «transposición» de la Carta. El legislador español ha publicado expresa y literalmente la CDF en el artículo $2{ }^{\circ}$ de la Ley orgánica de ratificación del Tratado de Lisboa: Pero no es en virtud de este tratamiento privilegiado de la Carta respecto de los Tratados como la CDF se incorpora al ordenamiento español.

La nota esencial de la CDF en lo que a su posición en el ordenamiento jurídico de los Estados miembros se refiere es, pues, su condicionalidad. La Carta no se impone a todos y cada uno de los actos de los poderes públicos nacionales de forma necesaria sino sólo condicionada, es decir, por decirlo con la literalidad de la propia Carta «únicamente cuando aplican el Derecho de la Unión». La condición es, pues, que los poderes públicos estatales estén dando aplicación al Derecho de la Unión. El Tribunal de Justicia viene precisando cuándo esto es así, partiendo de su declaración de principio en el asunto Akerberg y al hilo de los diferentes supuestos sometidos a su consideración ${ }^{31}$.

Conviene reconocer que son dos diferencias de peso las que separan una y otra funcionalidad. Lo que importa ahora subrayar es que se trata de la misma Carta. Porque de aquí resulta la singularidad funcional de esta pieza constitucional en el

28 H.D. JaRAss, «Charta der Grundrechte der europäischen Union. Kommentar», Munich, C.H. Beck, 2010, p. 5.

29 Asunto Digital Rights Ireland y Seidlinger y otros (C-293/12). Sentencia de 8 de abril de 2014.

30 Asunto Hans Akerberg Fransson (C-617/10), sentencia de 7 de mayo de 2013.

31 D. Tнум, «Blaupausenfallen bei der Abgrenzung von Grundgesetz und Grundrechte-Charta», Die öffentliche Verwaltung, 67 (2014), pp. 941-951. 
conjunto de la comunión constitucional que es la Unión. Y a estos efectos no tiene sentido en mi opinión recordar el efecto directo del Derecho de la Unión, en su globalidad. En conclusión, la CDF aparece hoy como el vértice de una constitucionalidad compartida, compartida por la Unión y los Estados miembros. Esto es así ya en virtud de la propia Carta. Pero el cuadro quedaría incompleto si se quedase aquí.

\section{EL «VALOR DE POSICIÓN» DE LA CARTA MÁS ALLÁ DE LA CDF: CONSTITUCIONALIZACIÓN ESPONTÁNEA DE LA CARTA}

La posición de la Carta en los ordenamientos constitucionales de los Estados miembros no se agota, en efecto, en las prescripciones del Derecho de la Unión, las cuales configurarían una posición mínima. Nada hay en la Carta y más generalmente en el Derecho de la Unión que impida el que los Estados miembros refuercen la presencia de la CDF en el interior de sus ordenamientos, ya sea otorgándoles una determinada fuerza más allá del ámbito de aplicación del Derecho de la Unión en el sentido del artículo 51 CDF, ya sea dándoles, dentro de ese ámbito un tratamiento o reconocimiento en términos sustantivos o procesales internos que el Derecho de la Unión no exige. Esto que vale para el ordenamiento de la Unión en general ${ }^{32}$, es aquí aplicable. Son estos «incrementos de protagonismo» de la CDF los que merecen ahora alguna atención.

El fenómeno es, para empezar, conocido en España, donde tenemos la temprana experiencia de la aplicación a la CDF del mandato interpretativo contenido en el artículo 10.2 C. Pero no es del caso español, suficientemente conocido, del que conviene ocuparse ahora ${ }^{33}$. Más interés tiene volver sobre la sentencia del Tribunal Constitucional austriaco de 14 de marzo de 2012, con toda la sencillez que su complejidad permite ${ }^{34}$.

La pronto llamada «Sentencia de la Carta» («Charta-Erkenntnis») recibió de forma inmediata la atención de la doctrina, con calificativos de «espectacular» ${ }^{35}$ y similares. Digamos muy resumidamente que, en virtud de esta sentencia, los contenidos nucleares de la CDF reciben la condición y el tratamiento de derechos constitucionales en el sentido del ordenamiento austriaco, en unas circunstancias,

32 Asunto Dzodzi. Sentencia de 18 de octubre de 1990 (C-297/88 y C-197/89).

33 La exposición de motivos de la Ley Orgánica 1/2008 (cit. n. ${ }^{\circ}$ 2), en una valoración digna de reseñarse, declara que el valor jurídico de la Carta, equiparado a los Tratados, que otorga el Tratado de Lisboa supone «un avance de considerable valor político, además de jurídico, en el proceso de construcción de la Unión y de la ciudadanía europea».

34 Para la relevancia de esta doctrina en el contexto de un tratamiento de la jurisdicción constitucional austriaca en su conjunto, cfr. Chr. GrabenwarTer, «Der österreichische Verfassungserichtshof», en A.v. Bogdandy/Chr. Grabenwarter/P.M. Huber, «Handbuch Ius Publicum Europaeum», Bd. VI, «Verfassungsgerichtsbarkeit in Europa: Institutionen», Heidelberg, C.F. Müller, 2016, pp. 413-469, 465-469.

35 M. PösCHL, cit. n. ${ }^{\circ} 23$, p. 587. 
con una argumentación y con unas consecuencias sustantivas, y sobre todo procesales, que paso a enunciar.

En relación con las circunstancias del caso debe decirse que, en dos asuntos diferentes, una nacional china y un nacional chino solicitan protección internacional en la República de Austria, en el caso de la una con el argumento de que ha herido a un policía en China y en el del otro porque puede verse impuesta allí una pena de prisión por deudas. Las autoridades administrativas austriacas consideran que las razones alegadas no merecen credibilidad o en todo caso que no se justifica la concesión del asilo. Hay que decir que en Austria las resoluciones administrativas en materia de asilo son recurribles ante un tribunal especializado (Asylgericht), cuyas decisiones sólo son recurribles, y por violación de «derechos constitucionales» ante el Tribunal Constitucional. Estas personas, sin embargo, invocan ante el Tribunal Constitucional precisa y únicamente un derecho fundamental de la $C D F$, concretamente el derecho a la protección judicial efectiva de su artículo 47. La queja es que el tribunal de asilo deniega la solicitada celebración de vista oral de forma previa a la resolución de su petición. En estas condiciones conviene señalar las características del Derecho nacional antes de exponer la respuesta del Tribunal.

A este respecto es importante señalar con toda brevedad, casi telegráficamente, lo siguiente: El Tribunal Constitucional es el tribunal competente para la protección de los «derechos constitucionales», en general, frente a leyes y disposiciones generales, así como frente a los actos de las administraciones públicas (no así frente a resoluciones judiciales del orden civil y penal). Ahora bien, desde la incorporación de Austria a la Unión es pacífica la primacía del Derecho de la Unión, con la importante particularidad de que éste hasta ese momento no venía siendo canon de enjuiciamiento para el Tribunal Constitucional ${ }^{36}$. Por otra parte y como es conocido, desde 1964 el CEDH tiene rango constitucional en Austria, lo que es tanto como decir que son «derechos constitucionales» en el sentido del ordenamiento jurídico austriaco. Y el CEDH, y esto ya no es peculiar a Austria, está llamado con arreglo a la Carta a determinar el contenido de los derechos que esta última proclama. Por otra parte, y como se ha avanzado, el control judicial de las resoluciones administrativas en materia de asilo se encuentra atribuido a un tribunal especial cuyas resoluciones sólo pueden ser objeto de recurso por violación de «derechos constitucionales» ante el Tribunal Constitucional. De todo este conjunto de circunstancias resultaba que la competencia del Tribunal Constitucional para conocer de las indicadas demandas basadas exclusivamente en un derecho fundamental «de la Carta» presentaba un problema.

El Tribunal Constitucional, ya se ha adelantado, llegará a la conclusión de que es competente para conocer de estas quejas por cuanto se fundamentan en un derecho fundamental que, aunque situado en la CDF, debía ser considerado un

36 Punto 4.2. (Sentencias $15.753 / 2000$ y 15.810/2000), con referencias doctrinales de primera hora.

UNED. Teoría y Realidad Constitucional, núm. 39, 2017, pp. 85-101 
«derecho constitucional» en el sentido del ordenamiento constitucional nacional. A esta conclusión se llega a través de un razonamiento que incluye diversos elementos.

La primera afirmación del Tribunal, ya se ha avanzado, es que su consolidada doctrina sobre el Derecho de la Unión como situado extramuros de su canon de enjuiciamiento no tiene que valer para la CDF. Pues, para empezar, una cosa son «los Tratados» y otra cosa es «la Carta», como resulta de la literalidad del artículo 6.1 TUE ${ }^{37}$. Pero, sobre todo, el cambio de doctrina vendría impuesto por el mandato derivado del principio de equivalencia: Con arreglo al Derecho de la Unión, los jueces nacionales están obligados a no dar a las posiciones jurídicas derivadas del Derecho de la Unión una tutela de peor calidad que la otorgada en supuestos similares, a las derivadas del Derecho nacional ${ }^{38}$. Es así que derechos y libertades coincidentes con el ahora invocado de la Carta son objeto de protección por el Tribunal Constitucional, el principio de equivalencia impondría que el Tribunal Constitucional asumiera la competencia de la protección de un derecho de la Carta.

Es aquí (punto 5.6) donde el Tribunal hace el pronunciamiento situado en la cabecera de estas páginas: $\mathrm{Al}$ resultado que se acaba de mencionar no cabe oponer el hecho innegable de que ya con anterioridad a la entrada en vigor de la Carta el TJUE había hecho valer los derechos fundamentales como principios generales, pues, como ya se ha recogido, no cabría equiparar en su valor a estos principios con los que resultan de un catálogo detallado de derechos y deberes ${ }^{39}$.

Es de decir que en este hilo argumental el Tribunal Constitucional tiene que enfrentarse con la heterogeneidad de los contenidos sustantivos de la CDF, en particular con la dicotomía derechos/principios: respecto de estos últimos no cabría hablar de una asimilación a los «derechos constitucionales», los cuales revelan «una estructura normativa por completo diferente» ${ }^{40}$. Pero respecto del derecho a la tutela judicial el tribunal no alberga dudas.

Para la jurisdicción administrativa el Derecho de la Unión sí es canon de enjuiciamiento, con un inequívoco deber de otorgarle primacía de aplicación (Anwendungsvorrang). En principio, pues, en cuanto parte del Derecho de la Unión, los derechos de la Carta serían únicamente invocables ante la jurisdicción administrativa. Si estas personas hubieran invocado el derecho a la tutela judicial derivado de la Constitución austriaca no habría habido problema en que el Tribunal constitucional hubiera conocido de la queja. Pero sólo citan la CDF, porque entienden, con razón, que al ser el asilo una materia situada en el ámbito de aplicación de ésta, la Carta es la que se aplica.

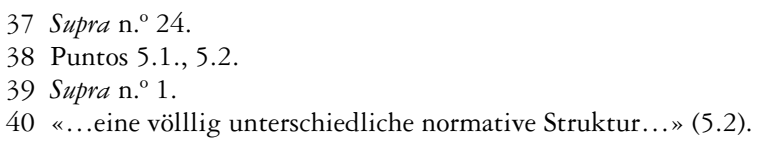


La sentencia de 14 de marzo de $2012^{41}$ fue recibida con división de opiniones por parte de la doctrina, mayoritariamente en sentido crítico $^{42}$. Así, M. Pöschl, extiende su crítica a la posición especial que el Tribunal asigna a la CDF (Sonderstellung $)^{43}$. Se han señalado algunas inexactitudes puntuales en la sentencia y, sobre todo, se han puesto de manifiesto los interrogantes que plantea la identificación de qué contenidos de la CDF tienen en Austria el carácter de «derechos constitucionales», con consecuencias para la competencia del Tribunal Constitucional. Chr. Bezemek, en cambio, aplaude la doctrina, «en parte por su carácter progresista, en parte por su esfuerzo por reivindicar para el Tribunal Constitucional la esfera de los derechos fundamentales, aspirando a una jurisprudencia más coherente en materia de derechos fundamentales en el seno de la justicia austriaca» ${ }^{44}$. Pero hay que reconocer que estas manifestaciones en sentido positivo no son las que más abundan en la doctrina.

Desde 2012 el Tribunal Constitucional Austriaco ha tenido ocasión de consolidar esta jurisprudencia ${ }^{45}$. Prescindiendo de un supuesto de reconocimiento de matrimonio homosexual en el que no se llega a entrar en el fondo por la evidente falta de conexión con el Derecho de la Unión, es sobre todo en su sentencia de 27 de febrero de 2014, donde el Tribunal consolida su doctrina, apreciando la inconstitucionalidad de un precepto de la Ley reguladora del Tribunal de Asilo como contrario a la CDF, al principio de Estado de Derecho y al de igualdad de trata de los extranjeros entre $\mathrm{si}^{46}$. Aparte de ello, el Tribunal reitera su doctrina, a la vez que desestima el recurso en un caso de discriminación inversa por razón de género, en materia de acceso a los estudios de medicina ${ }^{47}$.

En suma, e intentando recapitular. La llamada «Sentencia de la Carta» hace varias cosas simultáneamente, lo que la vuelve particularmente compleja. Hay en ella un elemento de reedición del acto de elevación de derechos fundamentales externos al rango constitucional, en este caso determinados contenidos sustantivos de la CDF. Hay una pulsión protectora de los derechos en el caso concreto, porque,

41 Hay que tener en cuenta que los votos particulares no están admitidos en la jurisdicción constitucional austriaca, lo que deja fuera de cuestión el conocimiento público de cualquier posible disenso en el interior del Tribunal. Sobre los diversos intentos de introducir esta figura, T. EHs, «Der VfGH als politische Akteur. Konsequenzen eines Judikaturwandels?», OZP — Austrian Journal of Political Science, 44 (2015), pp. 15-27.

42 Supra, n. ${ }^{\circ} 23$.

43 Ibid., p. 591.

44 Cit. n. ${ }^{\circ} 22$, p. 95.

45 Situando la doctrina austriaca en el contexto europeo, cfr. C. Franzius, «Strategien der Grundrechtsoptimierung in Europa», EuGRZ 2015, pp. 139-153, 148 ss.

46 ECLI:AT:VFGH:2014:G86.2013.

47 Sentencia de 5 de marzo de 2015 (ECLI:AT:VFGH:2015:B533.2013): «En el caso del artículo 21.2 CDF se trata - ya sólo como consecuencia del carácter estructuralmente igual de esta prohibición de discriminación respecto de la recogida en el artículo 7.1 LCF o en el artículo 14 CEDH - de una garantía de la CDF que tanto por su formulación como por su precisión resulta igual a los derechos garantizados por la Constitución Federal austriaca, con lo que no manifiesta una estructura normativa completamente diferente» (punto 27). 
tal como lo he entendido, en el caso de las demandas de asilo, donde por lo demás el derecho fundamental que rige es el de la Carta, sólo el Tribunal Constitucional estaba en ocasiones de examinar la queja constitucional. Hay una preocupación por mantener la unidad y la coherencia en materia de derechos fundamentales frente a actos administrativos. La construcción argumentativa es, sin duda, arriesgada, como también es cierto que el tribunal se enfrentaba a una dificultad para explicar el cambio doctrinal. El entendimiento que la sentencia hace del mandato del principio de equivalencia puede ser discutido, pero posee lógica.

Llegados al final, la cuestión de fondo que plantea esta sentencia sería la que resulta de la cita que encabeza estas páginas: ¿Lleva verdaderamente razón el juez constitucional austriaco al declarar que el valor de un catálogo de derechos y deberes fundamentales no es comparable al que puedan tener las diversas "posiciones jurídicas», se entiende que también fundamentales, que quepa ir decantando a partir de los principios generales del Derecho de la Unión? Es una pena que la sentencia no haya desarrollado las razones que le llevan a esta declaración, que no tenían necesariamente que considerarse obvias.

En este pronunciamiento hay nada menos que una preferencia, en materia de derechos fundamentales, por el derecho expresado en un documento escrito proclamado solemnemente con valor jurídico constitucional, frente a la extracción judicial de los mismos a partir de un trabajo de deducción y de construcción de principios generales inspiradores del ordenamiento jurídico en cuestión. Esto es lo que en el pasaje en cuestión se dice y hay que reconocer al respecto que, o bien se entraba de verdad en la materia, y para eso se necesitaban unas pocas páginas, o simplemente se dejaba apuntado, como aquí se ha hecho.

El Tribunal, como señalé al comienzo, ha hablado de «Geltung», cuya traducción en términos de teoría de la norma jurídica es el de «validez», un término binario que no admite situaciones intermedias. He considerado, sin embargo, que el Tribunal utiliza el término con un sentido más amplio de la palabra, que lo aproximaría al de «valor», algo ya susceptible de graduación: El «valor», en términos de eficacia jurídica, de una declaración de derechos como la CDF sería superior (no sería «comparable») al de un «fondo de derechos fundamentales», digámoslo así, decantado judicialmente.

¿Es esto así? Si tuviera que pronunciarme diría que la CDF tiene un valor que el modelo subsistente en el apartado 3 del art. 6 TUE no tiene. Pero, ¿de qué tipo es este valor? Intuyo que la positivación de los derechos y libertades incorpora un valor democrático, insufla democracia a los derechos, de un modo que la decantación judicial del viejo paradigma no alcanza a hacerlo. Y esto lo hace ahora la CDF, con una serie de consecuencias a las que he aludido brevemente. Pero, obviamente, no es sólo una cuestión de democracia. La Carta, como se ha señalado ${ }^{48}$, acerca los derechos a los ciudadanos, facilita en términos prácticos su

48 M. PösCHL, cit. n. ${ }^{\circ} 23$, p. 589. 
invocación, como facilita, en el caso de la Unión, a los jueces nacionales la confrontación del Tribunal de Justicia con ellos. Son expresión indudable del cambio de paradigma más arriba aludido. Con la CDF cualquier sombra de instrumentalidad de los derechos en el contexto de la Unión desaparece, para otorgarles definitivamente su condición de «fines en sí mismos». Ahora bien, ¿permiten estas apreciaciones sostener un «mayor valor», en términos de eficacia jurídica, de la CDF frente al modelo existente en solitario hasta 2009? Parece desde luego complicado. Y sin embargo, qué duda cabe de que, con la CDF, los derechos fundamentales han dado un salto, sin que sea necesario calificarlo de cualitativo, sí evidente en lo que a su propia posición en el sistema de protección en el Derecho de la Unión se refiere. Incluso puede afirmarse que es la posición de los derechos fundamentales, como tales, en el Derecho de la Unión, la que, con la CDF, se ha visto reforzada en el Derecho de la Unión en su conjunto. En definitiva, la constitución de la UE, como representación, da así un paso más en su consolidación.

Todo esto ha sido captado, en mi apreciación, por el Tribunal Constitucional austriaco en su jurisprudencia sobre la CDF. Su sentencia de 14 de marzo de 2012 no es, por ello, solamente importante para el ordenamiento constitucional de un determinado Estado miembro. Por el contrario, se trata de una doctrina que, más allá de las particularidades de este ordenamiento, tiene capacidad para inspirar a otros tribunales situados en la «liga de tribunales constitucionales europeos», acuñada por Vosskuhle. Y, por fin, es también positivo que todo esto, en un nuevo servicio a la jurisdicción constitucional en el espacio jurídico ${ }^{49}$ europeo, lo haya hecho este tribunal, precisamente.

TitLE: The Place Value of the Charter of Fundamental Rights of the European Union in the european constitutional "communion"

AвSTRACT: Metaphorically speaking the Charter of Fundamental Rights of the European Union $(C F R)$ is the venous system through which the culture of fundamental rights circulate nowadays in the constitutional space of the Union. This emerging strategic condition of the CFR is not to be read as the sole and direct consequence of Union Law as interpreted by the ECJ. Member States apex courts are also playing a crucial role in consolidating the place value of the CFR. The present contribution examines the dual functionality of the CFR both in the legal order of the Union and that of the member States. Thereby it pays particular attention to the ruling of the Austrian Constitutional Court dated March 14th 2012, better known as "the Charter decision", as well as the ensuing case law.

Resumen: Metafóricamente hablando la Carta de los Derechos Fundamentales de la Unión Europea es como el sistema venoso por el que actualmente circula la cultura de los derechos fundamentales en el espacioconstitucional de la Unión. Esta condición estratégica emergente de la Carta no debe entenderse como

49 Proponiendo 'espacio jurídico’ ('legal space’) como categoría preferible hoy día a través de Europa a la de 'ordenamiento jurídico' ('legal order'), A. v. BogDAndy, «European Law Beyond 'Ever Closer Union'. Repositioning the Concept, its Thrust and the ECJ's Comparative Methodology», European Law Journal, 22 (2016), pp. 519-538. 
consecuencia exclusiva y directa del Derecho de la Unión interpretado por el Tribunal de Justicia de la Unión. Los tribunales de los Estados miembros también desempeñan un papel crucial en la consolidación del valor de posición de la Carta. Este trabajo analiza la funcionalidad dual de la Carta, en el ordenamiento jurídico de la Unión y en el de los Estados miembros. Para ello se presta especial atención a la decisión del Tribunal Constitucional austriaco de 14 de marzo de 2012, más conocida como la "Decisión sobre la Carta", y a la jurisprudencia que deriva de ella.

KEY wORDS: Charter of Fundamental Rights, European "legal space", multi-level Constitution, Constitutional Courts.

Palabras Clave: Carta Europea de derechos fundamentales, espacio jurídico europeo, constitución multinivel, tribunales constitucionales.

FECHA DE RECEPCIÓN: 15.01.2017

FECHA DE ACEPTACIÓN: 01.02.2017 
